\title{
Voluntary Counselling and Testing for HIV Among Allied Workers in Rural Area of Nigeria: Evaluation of Community-Based Interventions
}

\author{
Onoja AJ', Sanni FO², Abiodun $\mathrm{PO}^{3}$, Onoja $\mathrm{S}^{1}$, Shaibu $\mathrm{J}^{1}$, Oguche $\mathrm{D}^{1}$, Adamu $\mathrm{I}^{1}$
}

${ }^{1}$ Research Department, African Health Project, Abuja, Nigeria, ${ }^{2}$ Departement of West African Breast Cancer Study, Lagos State University Teaching Hospital, Ikeja, Lagos State, Nigeria, ${ }^{3}$ Department of National Integrated Specimen Referral Network, AXIOS International, Utako, FCT, Abuja, Nigeria.

\section{ABSTRACT}

Introduction: Knowledge of human immunodeficiency virus status is a key tool in the fight against the spread of the human immunodeficiency virus epidemic.

Objectives: This study sought to evaluate the impact of community-based intervention towards the prevention and control of human immunodeficiency virus on the voluntary testing for human immunodeficiency virus among allied workers in rural Bonny Kingdom of Rivers, State, Nigeria.

Methods: The study comprised two quantitative surveys; the baseline survey conducted before a three years human immunodeficiency virus prevention intervention programs and the post-intervention survey conducted after the interventions. A structured questionnaire was employed to collect information from a representative sample of the allied workers aged 15-49 years. The questionnaire item for this survey is broadly divided into six categories comprising the basic socio-demographic information, the knowledge of HIV testing, desire for HIV testing, self and solution efficacy, access to products and services including voluntary counselling and testing. Data were analyzed using SPSS version 25.0.

Results: The study comprised 419 participants in the baseline and 587 in the post-intervention survey. The overall knowledge of voluntary counselling and testing services was $76.8 \%$ of which $37.5 \%$ have been tested and $88.9 \%$ of which $68.0 \%$ have been tested at both surveys. Three of every $5(67.0 \%)$ had the desire to be tested at baseline while- 4 of every $5(81.1 \%)$ were willing to be tested at post-intervention. The major reasons for unwillingness to be screened include poor perception about voluntary counselling and testing and feeling of not being at risk. The prevalence of human immunodeficiency at baseline was $8.5 \%$ and $2.0 \%$ at the post-intervention survey with a prevalence ratio of 4.3 ( $p<0.0001$ ]. Human Immunodeficiency Virus (HIV) prevalence was $12.4 \%$ among women compared $4.8 \%$ in men at baseline. The prevalence among adolescents was $12.0 \%$ and $10.1 \%$ among singles.

Conclusions: This study has demonstrated that the struggle to prevent and control human immunodeficiency can be successful if intervention programs are put in place, particularly in rural communities where acquired immunodeficiency syndrome related information is limited.

Key words: HIVIAIDS, Intervention programme, Voluntary counselling and testing

DOI: https://doi.org/10.3126/ijosh.v10i1.29190

\section{Introduction}

he prevalence of human immunodeficiency virus (HIV) among adults (15-49 years) is $1.5 \%$

Date of submission: 29.05 .2020

Date of acceptance: 30.06 .2020

\section{Corresponding Author}

Dr. Ali Johnson Onoja

Research Department, African Health Project, Abuja, Nigeria

Phone number: +2348056793961

Email: onojaali@yahoo.com in Nigeria, being the second-largest HIV epidemic country in the entire world. ${ }^{1}$ Nigeria is also among the countries with the highest new HIV infections in subSaharan Africa. ${ }^{1}$ According to the 2018 report of the Joint United Nations Program on HIVIAIDS (UNAIDS) ${ }^{2}$, about 1.9 million Nigerians were living with HIV with 0.65 incidences per 1000 uninfected people of all ages.

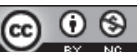

This journal is licensed under a Creative Commons AttributionNon Commercial 4.0 International License. 
The prevalence of HIV among Nigerian adults (15-49 years) was estimated at $1.5 \%$ with 53,000 deaths and 130,000 newly infected people in $2018 .^{2}$

The recent report of the National Agency for the Control of AIDS (NACA) ranked Rivers State third-highest HIV prevalent (3.8\%) behind Aiwa-lbom (5.6\%) and Benue $(4.9 \%)$ States in Nigeria. ${ }^{3}$ The goal of the vision 90 90-90 targets was that $90 \%$ of the people living with HIV will be aware of their status by 2020 and $90 \%$ of these people will be on HIV treatment and viral load suppression will be achieved in $90 \%$ of people on HIV treatment. $^{2}$ This goal is still far from being achieved despite that we are already in the year 2020 because the United States Agency for International Development (USAID) recent report shows that $67 \%$ of people living with HIV (PLWH) knew their status; $53 \%$ of them were on treatment and $43 \%$ were virally suppressed. ${ }^{2}$

The uptake of HIV counselling and testing remains poor in Nigeria. ${ }^{4}$ There are several barriers to HIV screening in Nigeria, especially in rural communities. The 2016 national report on HIV testing indicated a low level of knowledge as a barrier to HIV testing in Nigeria. ${ }^{5} \mathrm{~A}$ study conducted in Rivers State identified low perception of HIV risk, fear of positive HIV test result, fear of stigmatization, fear of discrimination, lack of trust on confidentiality by health workers. ${ }^{6}$ Low perception of sexual risk was identified as a major barrier for HIV testing in Uganda; ${ }^{4}$ stigmatization and limited information were identified as the major barriers in China; ${ }^{7}$ fear of positive HIV result and the unfavorable consequences, and misconception of HIV were identified as barriers to HIV testing in Zambia. ${ }^{8}$

Allied workers in rural areas are vulnerable to HIV infection because of their separation from spouses and their exposure to sex workers. The social and cultural perception of these people represents an average perception of the entire population. Hence, the need for intervention towards improving HIV testing in the struggle to achieve vision 90-90-90. Knowledge of HIV status is very important in the fight against the spread of the HIV epidemic. Unfortunately, only $10 \%$ of the people living in low resource settings have access to HIV testing services. ${ }^{9}$ Home-based testing and counselling have been proven as one of the best strategies towards improving HIV testing in rural communities, ${ }^{10}$ but this can be made possible through effective community-based intervention. Various studies have around the globe piloted the effectiveness of community-based interventions on HIV counselling and testing, ${ }^{11}$ but information on rural allied workers is very limited. This study sought to evaluate the impact of community-based intervention towards the prevention and control of HIV on the voluntary testing for HIV among allied workers in rural Bonny Kingdom of Rivers, State, Nigeria.

\section{Methods}

This study was carried out in Bonny kingdom located in an oil-rich coastal area of Rivers State. It covers an area of about $2.72 \mathrm{sq} . \mathrm{km}$. Over 30,000 people are living in Bonny. Due to the sitting of the gas plant (some $\$ 30$ Billion investment in oil terminals and natural liquid gas production), Nigerians of 'all walks of life' from other tribes, and professional foreign expatriate staff employed by the company (allied workers) have settled in, either on permanent or transient bases. Interestingly as witnessed in other parts of the globe the presence of Nigeria LNG Limited (NLNG) has also attracted other service-based industries. Anecdotal evidence revealed that several of the immigrant residents do not have their families staying with them on the Island.

Due to high incidence of HIV in Bonny kingdom, a pre-intervention survey was carried out in 2006 by the Society for Family Health which was used as a base document in the initiation of a three years (20082011) HIVIAIDS prevention intervention program. This survey of HIVIAIDS-related information was important to create an effective HIVIAIDS intervention in the Island, accurate baseline data were obtained from the different groups.

The community-based interventions include enlightenment programs, training, free HIV counselling and testing, distribution of condoms and referral and follow-up services for HIV-positive persons. Awareness and HIV education were carried out through handbills, posters, community meetings, workplace sensitization, drama, radio and televisions programs. The radio and television programs include 'Jann Kunne film', 'AIDS and You', 'Ireti alaafia (Hope for wellbeingRadio and Television)', 'One thing at a time', 'Gari muna fata' (A radio drama program), 'Odejinjin' (Television program), and 'Abule oloke merin' (a radio drama program on HIVIAIDS). After three years of intervention, the effectiveness or benefit of the various kinds of interventions was assessed on key elements on knowledge, attitudes and practices, and beliefs using information extracted from this post-intervention survey. 
This quantitative survey was carried out among allied workers in the Bonny Kingdom, using a structured questionnaire among a representative sample of the general population aged $15-49$ years. The questionnaire item for this survey is broadly divided into six categories. The first aspect contains sociodemographic information, the second one dealt with issues around the knowledge of HIV testing, desire for HIV testing, self and solution efficacy; access to products and services including Voluntary Counselling and Testing (VCT).

The aim is to compare the findings of the survey before intervention with the findings of the present survey (after intervention) to assess the impact of the intervention program. The sample size comprised of 419 allied workers in the pre-intervention survey and 587 in the post-intervention survey. There were more subjects in the post-intervention survey because more people participated in VCT program and were willing to participate in the survey, unlike the pre-intervention survey when most people were unwilling to participate due to wrong perceptions of HIV. Data were inputted with CashPro and transferred to SPSS version 25.0 for analysis.

Ethical approval was obtained from the National Health Research Ethics committee (NHREC), Federal Ministry of Health for the seroprevalence aspect of the study. Additionally, in line with the National Guidelines for mobile Voluntary Counselling and Testing (VCT), the respondents' informed consent was sought and signed before the test was administered. Respondents also had the option of opting out or up taking the test after the counselling process and confidentiality was strictly preserved with the client not forced to give out names as their VCT forms were assigned codes. Although the code was linked to the questionnaire number, however, this has no link to the person and confidentiality was guaranteed.

\section{Results}

There were 419 participants in the baseline survey and 587 in the post-intervention survey. Males and females were $221(52.7 \%)$ and $198(47.3 \%)$ in baseline while post-intervention comprised $338(57.6 \%)$ and 249 $(42.4 \%)$ respectively. Both surveys participants were mostly within age $15-24$ years (228; 69.2\%-baseline) and $(347 ; 59.5 \%$-post-intervention).

\section{Knowledge of where to get an HIV counselling and test services}

The survey sought information on the level of awareness and use of voluntary counselling and testing services among the respondents in the Bonny Kingdom. The respondents were asked if they knew of a place where they could get HIV testing services. This was aimed at assessing the availability of VCT services in its Bonny. The overall knowledge of VCT services among the respondents at baseline was $76.8 \%$ of which $37.5 \%$ have been tested for HIV. For post-intervention respondents, the overall knowledge was $88.9 \%$ and $68.0 \%$ have been tested. The knowledge of VCT services was higher in the intervention arm across all socio-demographic characteristics of the respondents than in the baseline. Also, higher proportions of respondents in all demographic categories in the postintervention arm have been tested for HIV as compared with the baseline survey. The knowledge and testing status increased with increase in the level of education in both surveys (Table1).

\section{The desire for HIV counselling and testing among respondents}

The opinions of respondents were sought about their willingness to access VCT services, this was done to determine whether the interventions have any impact on VCT services uptake among the allied workers. The baseline survey shows that about three of every five (67.0\%) had the desire to be tested for HIV while the post-intervention survey shows a to four of every five $(81.1 \% 5)$ allied workers were willing to be tested. It was discovered that less than half $(47.2 \%)$ of well-educated (post-secondary) participants in the baseline survey had the desire to be tested for HIV. However, these groups had the highest percentage of those who were willing to access VCT services in the post-intervention survey (Table 2).

\section{Reasons for willing to access VCT services}

The reasons why some study participants were willing to access VCT services are presented in Figure 1. The major reasons why respondents in the baseline survey desired to have HIV tests was just to know their status $(88.3 \%)$ and to reduce fear and anxiety $(12.1 \%)$. Very few access VCT services for marriage (28\%) and employment purposes (1.4\%). Due to the positive impacts of the intervention programs, more people desired to do HIV tests before getting married $(72.1 \%)$ and to know their status $(47.9 \%)$. 


\section{Reasons for Not willing to access HIV counselling and testing}

Figure 2 presents reasons for unwilling to access VCT services among respondents in both surveys. The majority of those who were unwilling to access VCT services in the post-intervention survey stated that they have been tested already (65.7\%) as compared to $36.8 \%$ in the baseline survey. Many of the respondents in both surveys were unwilling to access VCT services because they believed they were not at risk, therefore, no need for HIV tests (52.7\% and $27.6 \%$ ) for baseline and post-intervention respectively. The proportion of those who did not see any benefit of knowing their status reduced from $18.4 \%$ in baseline to $7.7 \%$ at post-intervention. Also, just $1.7 \%$ people opined that nothing could be done about HIV in post-intervention as compared to $11.8 \%$ in the baseline survey.
HIV prevalence rate among Allied workers in the Bonny Kingdom

Table 3 shows the prevalence of HIV among allied workers in Bonny kingdom. Among the participants tested for HIV, the HIV prevalence was $8.5 \%$ in the baseline as compared to $2.0 \%$ in the post-intervention. The prevalence ratio of baseline to post-intervention was 4.3 [Cl (2.1-9.0); $p<0.0001]$. HIV was more prevalent among women $12.4 \%$ in Bonny as compared to men $(4.8 \%)$ in baseline and higher than postintervention with $2.0 \%$ and $2.5 \%$ for women and men respectively. The prevalence ratio in women was 9.9 $(p<0.0001)$, which is 5.2 times higher than the 1.9 prevalence ratio seen in men $(p=0.225)$. HIV prevalence was also higher among age 15-24 in baseline (12.0\%) as compared to other age groups, though reduced to $2.0 \%$ in post-intervention. The prevalence of HIV was also higher among singles in baseline survey $10.1 \%$ than $6.5 \%$ seen in married. There was a reduction in these values to $1.9 \%$ after the interventions.

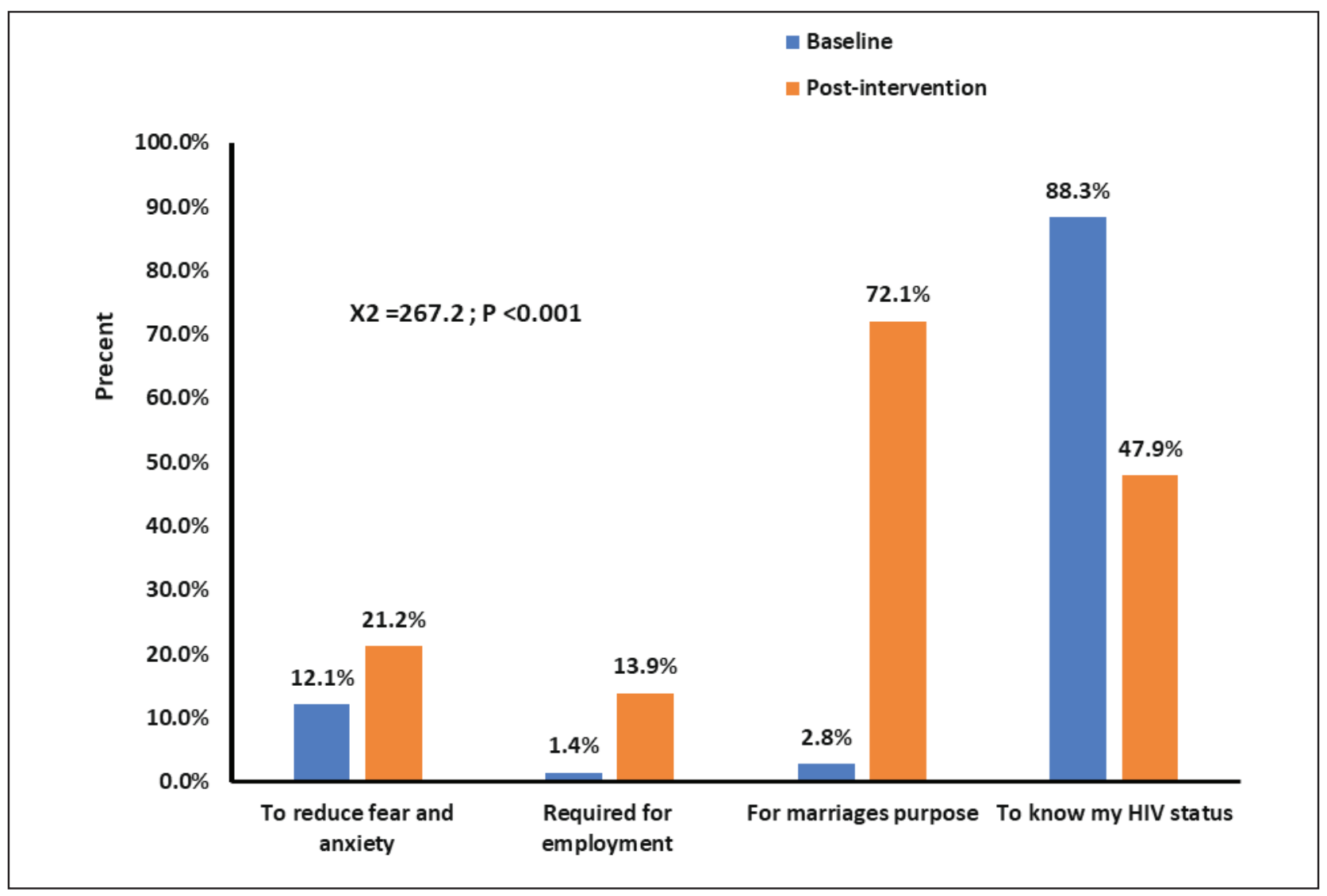

Figure 1: Respondents' reasons for desiring to access VCT services 


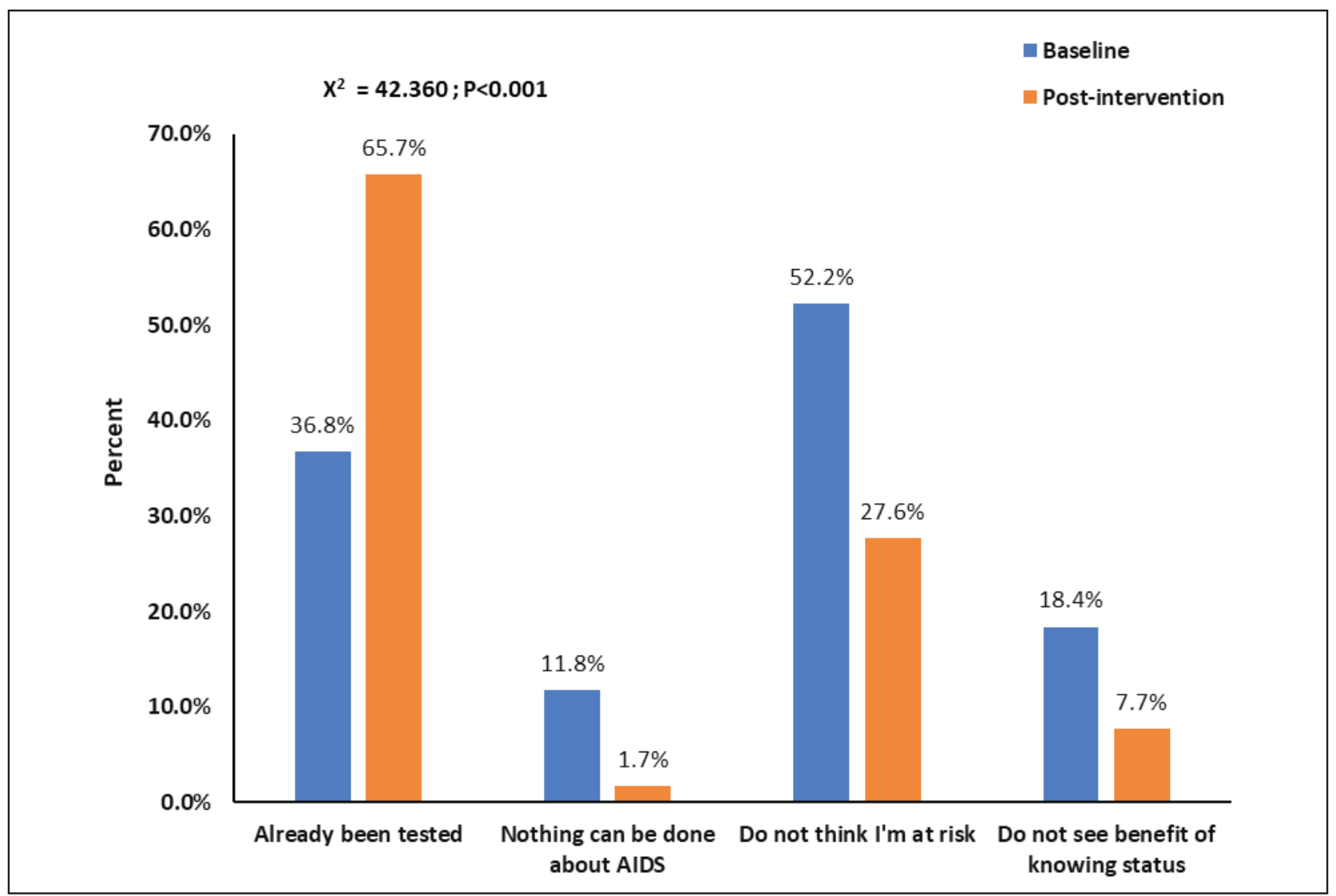

Figure 2: Respondents' reasons for not willing to access VCT services

Table 1: Respondents' knowledge of where to access HIV testing service and test status

\begin{tabular}{|c|c|c|c|c|c|c|}
\hline \multirow[b]{2}{*}{ Characteristics } & \multicolumn{3}{|c|}{ Baseline $(n=419)$} & \multicolumn{3}{|c|}{ Post-intervention ( $n=587$ ) } \\
\hline & $\begin{array}{c}\text { Know where } \\
\text { to test }\end{array}$ & $\begin{array}{c}\text { Ever had a } \\
\text { test }\end{array}$ & Total & $\begin{array}{c}\text { Know where } \\
\text { to test }\end{array}$ & $\begin{array}{c}\text { Ever had a } \\
\text { test }\end{array}$ & Total \\
\hline \multicolumn{7}{|l|}{ Sex } \\
\hline Male & $180(81.4)$ & $92(41.6)$ & 221 & $295(87.3)$ & $203(60.0)$ & 338 \\
\hline Female & $143(72.2)$ & $66(33.3)$ & 198 & $225(90.5)$ & $189(75.9)$ & 249 \\
\hline \multicolumn{7}{|l|}{ Level of education } \\
\hline No formal education/Primary & $45(51.1)$ & $15(17.0)$ & 88 & $32(61.4)$ & $17(33.3)$ & 52 \\
\hline Secondary & $161(78.9)$ & $61(29.9)$ & 204 & $319(90.0)$ & $223(62.9)$ & 354 \\
\hline Post-Secondary & $117(92.1)$ & $82(64.6)$ & 127 & 169 (93.3) & $151(83.6)$ & 181 \\
\hline \multicolumn{7}{|l|}{ Age group } \\
\hline $15-24$ & $74(74.7)$ & $24(24.2)$ & 99 & $137(83.3)$ & $106(64.2)$ & 165 \\
\hline $25-34$ & $149(78.0)$ & $76(39.8)$ & 191 & $165(90.7)$ & $144(79.2)$ & 182 \\
\hline 35-above & $100(77.5)$ & $58(45.0)$ & 129 & $218(90.8)$ & $147(61.3)$ & 240 \\
\hline \multicolumn{7}{|l|}{ Marital status } \\
\hline Single & $161(79.3)$ & $63(31.0)$ & 203 & $210(91.6)$ & $151(66.1)$ & 229 \\
\hline Ever married & $162(75.0)$ & $95(44.0)$ & 216 & $294(87.0)$ & $232(68.5)$ & 338 \\
\hline \multicolumn{7}{|l|}{ Length of stay in Bonny } \\
\hline Less than one year & $77(77.8)$ & $37(37.4)$ & 99 & $75(81.0)$ & $46(50.0)$ & 92 \\
\hline $1-3$ years & $101(78.3)$ & $48(37.2)$ & 129 & $193(90.0)$ & $144(67.1)$ & 214 \\
\hline 4years-above & $145(75.9)$ & $73(38.2)$ & 191 & 216 (76.9) & 167 (59.3) & 281 \\
\hline Total & $322(76.8)$ & $157(37.5)$ & 419 & $522(88.9)$ & $399(68.0)$ & 587 \\
\hline
\end{tabular}


Ali Johnson Onoja et al.

Table 2: Desire for HIV counselling and testing among respondents

\begin{tabular}{|c|c|c|c|c|}
\hline \multirow{2}{*}{ Characteristics } & \multicolumn{2}{|l|}{ Baseline } & \multicolumn{2}{|c|}{ Post-intervention } \\
\hline & Desire to have a test & Total & Desire to have a test & Total \\
\hline \multicolumn{5}{|c|}{ 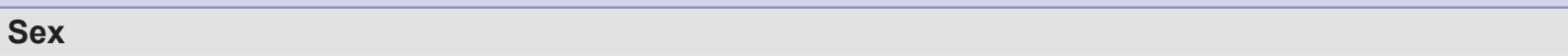 } \\
\hline Male & $152(68.8)$ & 221 & $265(78.5)$ & 338 \\
\hline Female & $129(65.2)$ & 198 & $208(83.7)$ & 249 \\
\hline \multicolumn{5}{|l|}{ Level of education } \\
\hline No education/Primary & $72(81.8)$ & 88 & $42(80.8)$ & 52 \\
\hline Secondary & $149(73.0)$ & 204 & $279(78.8)$ & 354 \\
\hline Post-Secondary & $60(47.2)$ & 127 & 154 (84.9) & 181 \\
\hline \multicolumn{5}{|l|}{ Age group } \\
\hline $15-24$ & $66(66.7)$ & 99 & 125 (75.9) & 165 \\
\hline $25-34$ & $140(73.3)$ & 191 & $151(83.0)$ & 182 \\
\hline 35-above & $75(58.1)$ & 129 & 198 (82.3) & 240 \\
\hline \multicolumn{5}{|l|}{ Marital status } \\
\hline Single & $147(72.4)$ & 203 & $199(87.0)$ & 229 \\
\hline Ever married & $134(62.0)$ & 216 & $291(86.0)$ & 338 \\
\hline \multicolumn{5}{|c|}{ Length of stay in Bonny } \\
\hline Less than one year & $63(63.6)$ & 99 & $79(85.7)$ & 92 \\
\hline $1-3$ years & $84(65.1)$ & 129 & $183(85.3)$ & 214 \\
\hline 4 years-above & $134(70.2)$ & 191 & 232 (82.5) & 281 \\
\hline Total & $281(67.0)$ & 419 & 476 (81.1) & 587 \\
\hline
\end{tabular}

Table 3: Prevalence rate among Allied workers in the Bonny Kingdom

\begin{tabular}{lcccc}
\hline \multirow{2}{*}{ Characteristics } & \multicolumn{2}{c}{ Baseline } & \multicolumn{2}{c}{ Post-intervention } \\
\cline { 2 - 5 } Sex & Tested (\%) & Prevalence (\%) & Tested (\%) & Prevalence (\%) \\
Male & & & & \\
Female & 51.7 & 4.8 & 54.1 & 2.5 \\
\hline Age group & 48.3 & 12.4 & 45.9 & 2.0 \\
15-24 & & & 0.0 & \\
$25-34$ & 24.9 & 12.0 & 29.3 & 2.0 \\
35-above & 48.8 & 7.1 & 33.0 & 1.0 \\
Marital status & 26.4 & 7.5 & 37.8 & 2.7 \\
Single & & & 0.0 & \\
Ever married & 54.2 & 10.1 & 42.5 & 1.9 \\
Not Stated & 45.8 & 6.5 & 54.9 & 1.9 \\
Total & 0.0 & 0.0 & 2.6 & 4.3 \\
\hline
\end{tabular}

\section{Discussion}

Voluntary counselling and testing (VCT) of HIV is the process of providing information to an individual to enable him/her makes an informed choice about being tested for HIV. This decision must be entirely the choice of the individual, and he or she must be assured that the process will be confidential. VCT is an entry point for prevention and care and is acknowledged internationally as an effective strategy for both HIVIAIDS prevention and care. Furthermore, it is an effective strategy for facilitating behaviors change VCT also constitutes a good platform for linkage between reproductive health and HIVIAIDS-related programmes.

Despite good knowledge VCT among baseline respondents, the proportion of those who have been tested for HIV was very low. Similar low level of VCT uptake has been reported in several studies across the world, particularly in communities without intervention. , $^{7,8,12-16}$ 
Due to poor self-risk assessment about HIVIAIDS, the majority of the respondents were unwilling to do HIV test because they believed they were not at risk of acquiring HIV infection. Other reasons for this low testing among baseline respondents include the belief that there is no benefit of knowing their status and while some had the opinion that since there was nothing that could be done about the disease. These misconceptions and poor self-risk assessment might be responsible for the alarming rate of HIV infection in Bonny. Right perception of HIV testing will help save the lives of family and friends of infected people. The status when known early will help infected people to receive the right counseling and treatment. Similar to this study, a study conducted in Osun State identified poor risk perception as one of the major barriers to the uptake of VCT among adults. ${ }^{4}$ Another study evaluated the challenges of HIV screening in Port-Harcourt, Rivers state found that the major barriers to HIV testing were poor HIV risk perception, fear of stigmatization and other negative consequences of being HIV positive. ${ }^{6}$ In Enugu, Nigeria, unwillingness to the screen was associated with the feeling of not being at risk, fear of a test outcome (positive result) and the cost of the test. ${ }^{17}$ The result of a study conducted in Burkina-Faso revealed that the poor of positive outcome was the major reasons why people were unwilling to screen. ${ }^{15}$ Similar findings have also been reported in $\mathrm{China}^{7}$ and in the rural community of Zambia where misconception and the fear of negative consequences stood as barriers to HIV testing. ${ }^{8}$

The impact of the interventions was seen in changing the workers' perception of HIV testing as the majority (119) stated that they have been tested for HIV in the post-intervention survey. This underscores the importance of HIV education (intervention) in rural communities. Such intervention should be channelled towards allied workers who are more HIV vulnerable in the course of their daily activities. High uptake of VCT services has also been reported in intervention cases such as home-based and community-based testing interventions..$^{10,11,18,19}$

Apart from changing the perception of the allied workers on VCT, this study found that the intervention recorded a huge success as more people got tested for HIV during the intervention than at the baseline. The major reasons the workers desired HIV tests in the baseline was to eliminate fear and anxiety. Not many were aware that it is necessary to do HIV test before getting married and not many wanted the test for employment reasons. However, the post-intervention survey revealed that the majority were willing to access VCT services before getting married in addition to just knowing their status. Also, the proportion of those who wanted the test for employment purposes increased significantly. This is mostly due to the community counselling and AIDS education given to owners of businesses and jobs during the intervention programme. Studies have reported similar high willingness to take up VCT among respondents due to intervention programmes. ${ }^{7,14,17}$

Rivers State has the third largest HIV prevalence in Nigeria. ${ }^{3}$ The findings of this study revealed that the majority of infected people reside in rural areas. This study found that the prevalence of HIV among allied workers in Bonny (before intervention) was $8.5 \%$, this is an alarming rate and justifies the intervention program executed in the community to prevent the spread of HIVIAIDS. HIV was rather very high among women in this community (12.4\%); this value is about 10 times higher than $2.0 \%$ found in post-intervention. The higher prevalence rate of HIV among women as compared to men in this study can be attributed to several factors but deeply rooted in gender inequality, culture and law in Nigerian communities. Nigeria is ranked $122^{\text {nd }}$ out of 144 countries with 'gender gap' or simply power inequality between men and women., 522 Also, due to the power imbalances between men and women, the latter often face barriers in selecting their sexual partner, whether to use contraception or not, the number of children or child-spacing, even access to healthcare. All these reason makes the women more vulnerable to HIV than men. ${ }^{6}$ Disproportionate HIV infection among women have been reported in Nigeria: $55.6 \%$ of the 1.8 million infected adults in 2018 were women. ${ }^{20}$ Also, studies have shown that new infections among women have almost double that of men $^{20}$, which has been attributed to certain factors such as violence, or rape against women and the violation of women's human rights. ${ }^{21}$

This study also recorded high prevalence (12.0\%) of HIV among adolescents (15-24 years) and singles (10.1\%) at the baseline survey. These findings emphasize the need to channel HIVIAIDS education towards young people in rural communities because this group is more vulnerable to HIV infections. This reflected in the result of the post-intervention survey that showed a sharp reduction in the prevalence to $2.0 \%$ and $1.9 \%$ in adolescent and singles respectively. The findings of 
this study agree with the reports of previous studies that about $7.0 \%$ of PLWH in Nigeria are adolescents (below 24 years), ${ }^{22}$ about $4.3 \%$ in the South-South, compared to $1.3 \%$ in the South East. ${ }^{23}$ This study also corroborated the previous report that HIV prevalence is higher among Nigerian young women because they are infected earlier in life than their male counterparts. ${ }^{24,25}$ The high prevalence of HIV among adolescents can also be due to early sex activities among Nigerian boys and girls. Studies in Nigeria found that $15 \%$ of girls and

\section{References}

1. Avert. Global information and education on HIV and AIDS: South africa. WwwAvertOrg [Internet]. 2020 [cited 2020 May 3]. Available from: https://www.avert. org/professionals/hiv-around-world/sub-saharanafrica/south-africa

2. UNAIDS. New survey results indicate that Nigeria has an HIV prevalence of [Internet]. In: UNIADS. 2020 [cited 2020 May 3];14-6. Available from: https://www.unaids.org/en/resources/presscentre/ pressreleaseandstatementarchive/2019/ march/20190314_nigeria

3. NACA/NAIIS. Nigeria Prevalence Rate - NACA Nigeria [Internet]. Natl. Nigeria: Agency Control AIDS NACA. 2019 [cited 2020 May 3]. Available from: https://naca.gov.ng/nigeria-prevalence-rate/

4. Amu EO, ljadunola KT, Bamidele JO, Odu OO. Barriers to and determinants of HIV counselling and testing among adults in Ayedaade Local Government Area, Osun State, Nigeria. J. Med. Sci. 2013;13(8):803-8.

5. NACA. National HIV strategy for adolescents and young people 2016-2020[Internet]. Natl Agency Control AIDS. 2016[cited 2020 May 3];58. Available from: http://www.ilo.org/wcmsp5/groups/public/--ed_protect/---protrav/---ilo_aids/documents/ legaldocument/wcms_532857.pdf

6. Tobin-West $\mathrm{Cl}$, Onyekwere VN. Human immunodeficiency virus screening in rural communities of Rivers State, Nigeria: Challenges and potential solutions. Ann Afr Med 2014;13(4):161-8.

7. Zhang $\mathrm{T}$, Zhang J, Gao $\mathrm{M}$, He N, Detels $\mathrm{R}$. Knowledge, attitudes and practices of voluntary HIV counselling and testing among rural migrants in central China: A cross-sectional study. Eur J Public Health. 2012;22(2):192-7.

8. Qiao S, Zhang Y, Li X, Menon JA. Facilitators and barriers for HIV-testing in Zambia: A systematic review of multi-level factors. PLoS One. 2018;13(2):1-27.

9. USAID. 2019-global-AIDS-update. United States: Communities Cent. 2019;121-38.
$4 \%$ of boys in Nigeria have sex before they reach the age of $15 .{ }^{23,25,26}$ The raised HIV vulnerability among younger Nigerians is attributed to the absence of the right sexual and reproductive health services. ${ }^{4-6,12}$

\section{Conclusion}

This study has shown that the struggle to prevent and control HIV can be successful if intervention programs are put in place, particularly in rural communities where AIDS-related information is limited.

10. Moshoeu MP, Kuupiel D, Gwala N, MashambaThompson TP. The use of home-based HIV testing and counseling in low-and-middle income countries: A scoping review. BMC Public Health. 2019;19(1):112.

11. Sulat JS, Prabandari YS, Sanusi R, Hapsari ED, Santoso B. The impacts of community-based HIV testing and counselling on testing uptake: A systematic review. J Heal Res. 2018;32(2):152-63.

12. Abiodun $O$, Sotunsa J, Ani F, Jaiyesimi E. Knowledge of HIVIAIDS and predictors of uptake of HIV counseling and testing among undergraduate students of a privately owned university in Nigeria. BMC Res Notes. 2014;7(1):1-8.

13. Fanta W, Worku A. Determinants for refusal of HIV testing among women attending for antenatal care in Gambella Region, Ethiopia. Reprod Health. 2012;9(1):1-13.

14. Ijeoma A, Ejikeme A, Theodora O, Chika O. Knowledge, attitude, willingness of HIV counseling and testing and factors associated with it, among long distant drivers in Enugu, Nigeria: an opportunity in reduction of HIV prevalence. Afr Health Sci. 2018;18(4):1088-97.

15. Kirakoya-Samadoulougou F, Yaro S, Deccache A, Fao P, Defer MC, Meda N, et al. Voluntary HIV testing and risky sexual behaviours among health care workers: A survey in rural and urban Burkina Faso. BMC Public Health. 2013;13(1).

16. Teklehaimanot HD, Teklehaimanot A, Yohannes M, Biratu D. Factors influencing the uptake of voluntary HIV counseling and testing in rural Ethiopia: A cross sectional study. BMC Public Health [Internet]. 2016[cited 2020 May 3];16(1):1-13. Available from: http://dx.doi.org/10.1186/s12889-016-2918-z

17. Aniebue PN, Aniebue UU. Voluntary Counseling and Willingness to Screen among Nigerian Long Distance Truck Drivers. Niger Med J. 2011;52(1):49-54.

18. Doherty $T$, Tabana H, Jackson $D$, Naik R, Zembe W, Lombard C, et al. Effect of home based hiv counselling and testing intervention in rural South Africa: Cluster randomised trial. BMJ. 2013;347(7915). 
19. Lippman SA, Pettifor A, Rebombo D, Julien A, Wagner RG, Kang Dufour MS, et al. Evaluation of the Tsima community mobilization intervention to improve engagement in HIV testing and care in South Africa: Study protocol for a cluster randomized trial [Internet]. Implement Sci 2017[cited 2020 May 3];12(1):1-13. Available from: http://dx.doi. org/10.1186/s13012-016-0541-0

20. UNAIDS. HIV in Nigeria [Internet]. UNAIDS. 2019 [cited 2020 May 3]. Available from: https://www. unaids.org/en/regionscountries/countries/nigeria

21. UNAIDS. 2015-Prevention Gap Report[Internet]. UNAIDS. 2016[cited 2020 May 3];76-80. Available from: http://www.unaids.org/sites/default/files/ media_asset/2016-prevention-gap-report_en.pdf

22. UNICEF. HIV Statistics - Global and Regional Trends - UNICEF DATA [Internet]. United Nations Int. Child. Fund 2019 [cited 2020 May 4]. Available from: https:// data.unicef.org/topic/hivaids/global-regional-trends/
23. Avert. HIV testing programmes Barriers to HIV testing uptake [Internet]. Avert. 2019 [cited 2020 Apr 13]. Available from: https://www.avert.org/professionals/hivprogramming/testing

24. UNAIDS. Global AIDS Update: Miles to go-closing gaps, breaking barriers, righting injustices. Report [Internet]. UNAIDS. 2018[cited 2020 May 3];268. Available from: http://www.unaids.org/sites/default/files/ media_asset/miles-to-go_en.pdf

25. UNAIDS. Blind Spot: Reaching out to men and boys. UNIADS. 2017[cited 2020 May 3];76. Available from: https://www.unaids.org/sites/default/files/media_asset/ blind_spot_en.pdf

26. Avert. HIV and AIDS in Nigeria[Internet]. Avert. 2019 [cited 2020 Apr 13]. Available from: https://www.avert. org/professionals/hiv-around-world/sub-saharan-africa/ nigeria

27. UNAIDS. Blind Spot: Reaching out to men and boys. UNAIDS. 2017;76. 